Article

\title{
A New Integrated Fuzzy Approach to Selecting the Best Solution for Business Balance of Passenger Rail Operator: Fuzzy PIPRECIA-Fuzzy EDAS Model
}

\author{
Slavko Vesković ${ }^{1}$, Željko Stević $^{2, *(\mathbb{D})}$, Darjan Karabašević ${ }^{3}$, Snježana Rajilić ${ }^{4}$, \\ Sanjin Milinković ${ }^{1}$ and Gordan Stojić ${ }^{5}$ (i) \\ 1 Faculty of Transport and Traffic Engineering, University of Belgrade, Vojvode Stepe 305, 11000 Belgrade, \\ Serbia; veskos@sf.bg.ac.rs (S.V.); s.milinkovic@sf.bg.ac.rs (S.M.) \\ 2 Faculty of Transport and Traffic Engineering, University of East Sarajevo, Vojvode Mišića 52, 74000 Doboj, \\ Bosnia and Herzegovina \\ 3 Faculty of Applied Management, Economics and Finance, University Business Academy in Novi Sad, \\ Jevrejska 24, 11000 Belgrade, Serbia; darjan.karabasevic@mef.edu.rs \\ 4 Bosnia and Herzegovina Railways Public Corporation, Kneza Miloša 105, 74000 Doboj, Bosna and Hercegovina; \\ snjezana_rajilic@yahoo.com \\ 5 Faculty of Technical sciences, University of Novi Sad, Trg Dositeja Obradovića 6, 21000 Novi Sad, Serbia; \\ gordan@uns.ac.rs \\ * Correspondence: zeljkostevic88@yahoo.com or zeljko.stevic@sf.ues.rs.ba
}

Received: 21 March 2020; Accepted: 12 April 2020; Published: 5 May 2020

\begin{abstract}
The analysis of operations of the passenger traffic operator in the Republic of Srpska (RS) showed that the volume of passenger transport has, for the last fifteen years, been in constant decline. It is of particular importance that the operator has, year after year, recorded a negative balance of business. The way out of the current unfavorable situation in the sector of passenger traffic is based on the application of Public Service Obligation (PSO) based on the Regulation 1370/2007. In order to solve the problems, seven realistically possible variants have been identified. This paper defines the criteria for selecting the best variant, as well as a new integrated fuzzy model for the selection of the best variant that will enable the operator to make a profit. To define the weights of criteria in this paper, we have used the fuzzy PIvot Pairwise RElative Criteria Importance Assessment (F-PIPRECIA) method, while for ranking and selection of the best variant, we have used the Fuzzy Evaluation based on Distance from Average Solution (F-EDAS) method. Results show that the seventh variant: "Increase in revenue from ticket sales and PSO services and reduction in costs" is the best solution in current conditions. Validation tests are performed with different scenarios and approaches and show that the model is stable. A validity test was created consisting of variations in the significance of model input parameters, testing of reverse rank, applying the fuzzy Measurement Alternatives and Ranking according to the COmpromise Solution (F-MARCOS), fuzzy Simple Additive Weighing (F-SAW) method, and fuzzy Technique for Order of Preference by Similarity to Ideal Solution (F-TOPSIS). As a part of the validation tests, Spearman's coefficient of correlation (SCC) in some scenarios is performed and weights of the criteria have been obtained using the Fuzzy Analytic Hierarchy Process (F-AHP) and Full Consistency Method (FUCOM).
\end{abstract}

Keywords: fuzzy PIPRECIA; fuzzy EDAS; railway; multi-criteria decision-making; transport policy

\section{Introduction}

One of the most important factors for the functioning and development of cities and regions according to Stojić et al. [1] is the public transport of passengers. The transport policy developed by the 
European Union (EU) has one of the main goals of overcoming the undesirable "modal split," in which road transport has a dominant position, strengthening the role of the railway, thus establishing the possibility of developing a transport system in the spirit of sustainable development. In fact, the Public Service Obligation (PSO) system represents a model for financing unprofitable transport services of a common interest of the country, the region, or the city and local community. Since the end of the 1960s, the EU has tried to improve and develop the concept of PSO in a number of sub-legal acts and regulations in all modes of transport, especially in rail and road public passenger transport (PPT). The basic idea of this concept was that the competent authority (state or local) should provide PPT on lines where the operator (transport company) cannot profitably operate practically, the public authority (ordering party) "buys" (negotiates) the transport service on the "open" market publicly and without discrimination. The volume and service quality, the number of lines and transportation units, the model of determining the amount of compensation for the execution of the service, as well as other mutual rights and obligations, are regulated by the contract. The operator is awarded a Public Service Compensation (PSC) for public transport. According to Regulation (EC) No 1370/2007 [2], the fee for covering the costs arising from the performance of the PSO should, therefore, be determined to prevent over-compensation, and it must be determined so that it does not exceed the amount corresponding to the net financial effect of an equal amount of effects, either positive or negative. The two basic terms that are contained in the new PPT system are: Public Service Obligation (PSO) and Public Service Compensation (PSC). For definition and details of these terms, see (Regulation (EC) No 1370/2007 [2]. By optimizing the PSO system in the PPT process, it is possible to achieve a number of effects, the most significant of which are: Increasing the volume of passenger transport (especially regional and suburban) and, in the worst case, a stoppage in the volume of transport, higher and more stable quality of transport services, reduction in travel costs, better and more efficient cost control, achieve the preconditions for the stabilization and reliability of the operation of railway companies that carry out the transport of passengers (operators). There is no universal and generally accepted model for defining the PSO and the PSC. For example, socio-economic and transport data for PPT services in European cities [3] show the ratio between subventions and operating costs, as well as the ratio of total revenue from the sale of tickets and total operating costs of PPT services in selected cities. According to the mentioned study, the revenues from the sale of tickets cover an average of $44 \%$ of the total operating costs of public transport companies. The second indicator shows the percentage of subventions in total operating costs of transport. On average, $48 \%$ of the total operating costs of transport are covered by subventions. This means that one-half of the total operating costs of transport is covered by sales revenues, while the other half comes from different subventions from the local, municipal, or national level.

The first aim of the paper refers to the development of a new integrated fuzzy PIvot Pairwise RElative Criteria Importance Assessment (F-PIPRECIA) - Fuzzy Evaluation based on Distance from Average Solution (F-EDAS) - model for solving the business balance of a passenger rail operator, which is harmonized with the EU transport policy. The second aim of the paper is the possibility to overcome the gap between different variants of solving concrete problems in, often, very different demographic, infrastructural, economic, and level-of-service quality levels. The design of the new integrated fuzzy model for the solution business balance of the passenger rail operator allows, within a reasonable time, the non-operational balance sheet of the passenger operator and even the possibility of achieving a rational profit. In order to solve the problem, seven realistic variants based on the combination of procedures, which, in different ways, lead to a defined goal, have been identified. In addition, the criteria for selecting the most favorable variant are defined, and the integrated model for selecting the most favorable variant should provide a positive balance.

This paper is structured as follows. Section 2 shows some brief backgrounds, while Section 3 shows the material and methods, the basic characteristics of railway transport in the Republic of Srpska (RS), its organization, and its current and future role. In addition, in this section, the proposed methodology is explained in detail. Section 4 shows the obtained results, applying a new developed 
fuzzy model, while Section 5 shows the extent of the validation tests. Section 6 presents the discussion and conclusions.

\section{Brief Background}

In the paper about public suburban transport in Germany, Beck [4] analyzes the state of the so-called commercial and non-commercial transport. In doing so, he notes that, after a decade of stagnation due to non-commercial transport, in the performance of the PSO, there is a positive change and the intensification of competition. The methodology for assessment of the future transport needs in PPT by Rojo et al. [5] is upgraded by the inclusion of the subjective value of time and readiness users pay for the improvement of services in order to determine the optimal concept of PSO. The system is optimized in two ways: With and without considering the economic business of the company in the function of the goal. Vesković et al. [6] used fuzzy logic for the assessment of the liberalization of rail passenger traffic on the example of Serbia, and one of the criteria in the model for assessment is PSO. Nash et al. [7] used quantitative and qualitative methods to investigate the impact on the cost of the vertical separation of railways in cases of a radical approach to restructuring. They are suspicious that reforming the railways through vertical and horizontal separation leads to cost savings. They state that precisely determining the methods and control of the distribution "of state money," subventions (PSO, maintenance and infrastructure development) have primarily led to cost reductions. In order to achieve the aims defined by the overall transport policy according to Ibarra-Rojas and Rios-Solis [8], cities and municipalities choose to subsidize PPT. These aims are different and range from providing transport options to all social categories to increase mobility for all residents. As a special advantage of these systems, Tirachini and Hensher [9] and Kim and Schonfeld [10] point out that the implementation of such a transport policy reduces the need for the use of personal vehicles. This, in turn, offers the opportunity to better manage urban space and transform the environment for the sustainable development of urban communities. In his paper, Van Reeven [11] developed a model aiming to demonstrate that the costs on the principle of consumer spending time do not provide justification for public transport subventions. PPT subventions are common in developing countries and are often justified by the availability of traffic accessibility, but not efficiency. In view of this justification, it is of interest to know how to use and distribute transport subventions.

To understand the idea behind public transport subsidies, Vuchic [12] and Hanson and Giuliano [13] emphasize that cities and municipalities do not subsidize operators, but the actual public transport service offered to citizens. In the absence of a subsidy, carriers are forced to charge the full cost of transportation for passengers through the price of tickets, which would lead to a significant reduction in transport demand and thus a decrease in traffic supply. Such a transport strategy implies, on the one hand, reduced mobility and, on the other, increased citizen dissatisfaction.

\section{Materials and Methods}

\subsection{Proposed Methodology}

The multi-criteria decision-making (MCDM) methods are widely used for the facilitation of the decision-making process in various fields [14-16]. The original developed MCDM methodology shown in Figure 1 was applied for selection of the best solution for the business balance of the passenger rail operator. 


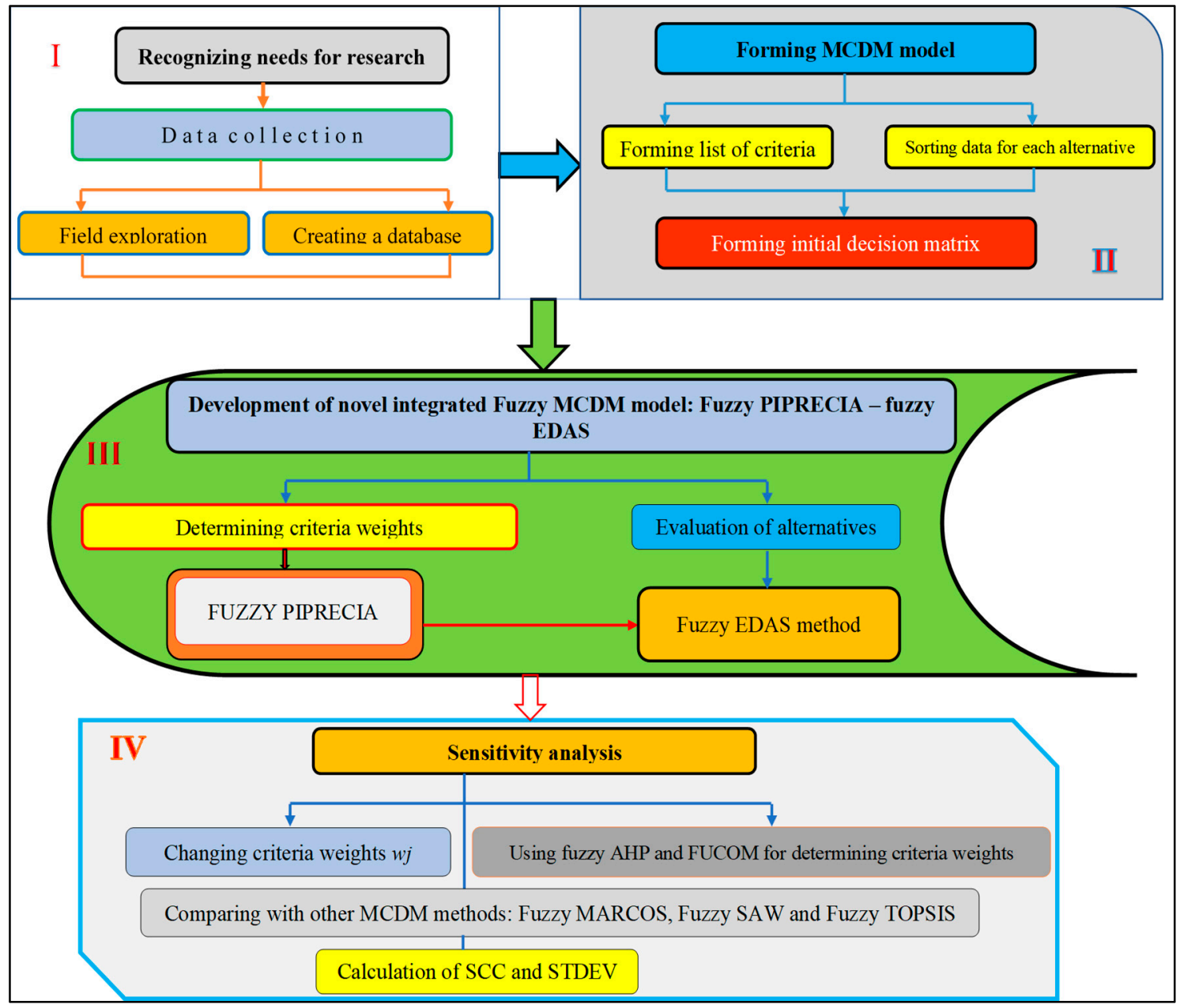

Figure 1. Proposed methodology.

As part of the first phase of the research, data were collected. After that, an adequate database on transport policy was created in order to obtain and to analyze their effects on the business operators. Based on the collected data and created base, the forming of the MCDM model represents the second phase of the proposed methodology. Five most important criteria, explained in detail in the further text, were considered, while seven different variants were identified. Based on such parameters, an initial fuzzy decision matrix was formed. The third part of the methodology represents the most important part of the research and consists of two steps that are causally linked both to each other and to the elements of the following phase. These steps represent the development of an original integrated fuzzy MCDM model. First, the significance of the criteria was determined using the F-PIPRECIA method [17] according to the assessment of three decision-makers. Evaluation of various variants for selecting the best solution for the business balance of the passenger rail operator was performed using the F-EDAS method [18]. The fourth phase of the methodology involves the validation and sensitivity analysis of the proposed model. It is implemented throughout a few steps, where the first step relates to variations in the significance of the criteria. All individual approaches are individually included in the calculation of the F-EDAS method and a comparative analysis is given with respect to the proposed model. Testing the influence of dynamic factors-of the reverse rank and calculation of the criteria weights using the Fuzzy Analytic Hierarchy Process (F-AHP) [19] and Full Consistency Method (FUCOM) [20] methods-is also a part of the validity test. The next step includes the comparison of the developed model with three other fuzzy MCDM methods: fuzzy Measurement Alternatives and Ranking according to the COmpromise Solution (F-MARCOS) [21], fuzzy Simple 
Additive Weighing (F-SAW) [22], and fuzzy Technique for Order of Preference by Similarity to Ideal Solution (F-TOPSIS) [23].

Finally, the Spearman's correlation coefficient (SCC) was calculated to determine the correlation of all obtained ranks across previously formed scenarios. As the F-PIPRECIA [17,24-26], F-EDAS [18,27-29], FUCOM [30,31], F-MARCOS [21], F-SAW [22,32], and F-AHP [23,33,34] methods have been exploited in the literature, their detailed algorithms are not presented.

\subsection{The Position of Public Transport Services (PTS) for Passengers by Rail in the Transportation System of the Republic of Srspka}

The Railways of the Republic of Srpska (RRS) have been established as a public transport company, and it is important to emphasize that by "under the railway traffic of interest for the Republic of Srpska," we mean "railway public passenger transport." Irrespective of commercial interest, RRS must have at their disposal adequate capacity (material and human) and organizational conditions for the provision of public transport services (PTS) for passengers. Therefore, the authorities of the Republic of Srpska exert significant impact on the results of operations and the balance sheet of the company. RRS, and the segment of the company that deals with passenger transport (passenger transport operations) in particular, must establish an original system of determining results (revenues, expenses, profit-loss) on the grounds of the public transport of passengers. The opening of the railways to competition in the market of transport services brought about a separation of management and accounts (balance sheet) of infrastructure and transport. Consistent realization of this process means that "RRS shall—through a special type of bookkeeping-present to its founder the state and the railway infrastructure costs compared to the costs of operators." Separate reporting of costs is aimed at expressing the impact of business segments upon the operating results, which are determined by the balance sheet. Therefore, it is necessary to separately determine the balance of infrastructure and the balance of transport (assets, debts, obligations, liabilities, equity, revenues, expenses, results), as well as the consolidated balance of the corporation. In its efforts to provide for the traffic of interest for the Republic of Srpska, the government participates through partial financing. This means that RRS provide funding for a part of the public transport system that is of interest for the Republic of Srpska. According to Gangwar and Raghuram [35], one of the options is structuring public private partnerships. The volume of passenger transport is in a constant downward trend, and the largest volume of transport was recorded in 1996, amounting to 1,648,000 of transported passengers, while in 2009, the RRS transported no more than 368,289 passengers. The negative trend has continued in the years to come, so in the last two years, the annual number was at the level of about 150,000 passengers. Financial results regarding passenger traffic have been made according to the planning documents: Annual report of RRS for 2014, and business plan for the period 2012 to 2014.

The revenue and expenditure plan in passenger traffic is projected at the level of the financial loss of over $-19,000,000 \mathrm{KM}$ for each considered year, which is why the plan of inflows and outflows of funds remains at the level of loss of $-26,869,280 \mathrm{KM}$ in 2012 to $-38,616,384 \mathrm{KM}$ in 2014 . The increase in expenditure in 2012 was by $67 \%$ higher compared to 2011 , amounting to $10,371,589 \mathrm{KM}$, and the revenues were lower by about $30 \%$, i.e., by $2,559,281 \mathrm{KM}$. The increase in expenditure in the said amount was the result of an increase in the following: Cost of fees for access and use of railway infrastructure in the amount of $\mathrm{KM}+5,458,404(+52 \%)$; cost of wages, salaries, and other employee benefits in the amount of $\mathrm{KM}+2,996,647(+29 \%)$, cost of materials for the work in the amount of $\mathrm{KM}+1,020,676(+10 \%)$, and costs of production services in the amount of $+966,014(9 \%)$ (Figure 2$)$.

The problem with the above, i.e., the problem with the operations in the reported period with a huge financial loss, lies in reduced business competitiveness of RRS as the operator at a future liberalized market of transport services, and, therefore, its uncertain business future. In this sense, the "experts" of the Railways of the Republic of Srpska have reduced passenger traffic for the 2008/2009 timetable by eliminating 22 passenger trains that were, by internal calculations, within the area of unprofitable business. 


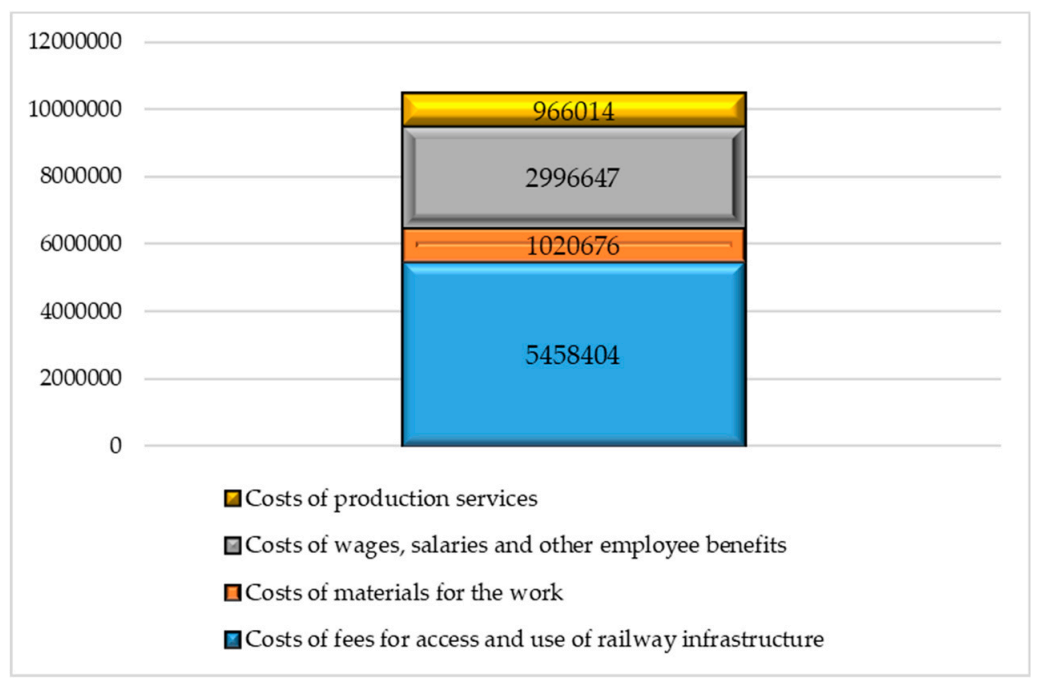

Figure 2. Increase in expenditures of Railways of the Republic of Srpska (RRS) for 2011-2012 years.

Reactions of passengers to this move were completely understandable, so the reduction in the number of trains by $25 \%$ (from 76 to 54 trains a day) led to a reduction in the number of passengers for close to $50 \%$, or to be more exact, by $45 \%$ in that same (first) year when they implemented the reduction in the number of trains (from 635,000 annually to 368,000). This trend of reducing the number of passengers due to an unsatisfactory timetable and reduced frequency of trains was carried out on almost all routes. The authorities of the Republic of Srpska noted that by this move, they achieved a reduction in operating costs of about 2,000,000 KM but failed to note the loss and reduction in income due to a drastic reduction in the number of passengers.

The downward trend in train numbers has led to an increase in the company's financial losses. It is true that the cost of doing business has been somewhat reduced (Figure 2), but revenue has fallen significantly, leading to greater financial losses (Figure 3). The financial loss of the company in 2011 amounted to 6,969,205 KM. In 2012, expenditures of KM 10,441,741 were still high, although they were somewhat reduced, but revenues were significantly lower and decreased by over KM 2.5 million so that the company's negative balance in fiscal 2012 increased to 19,970,227 million KM.

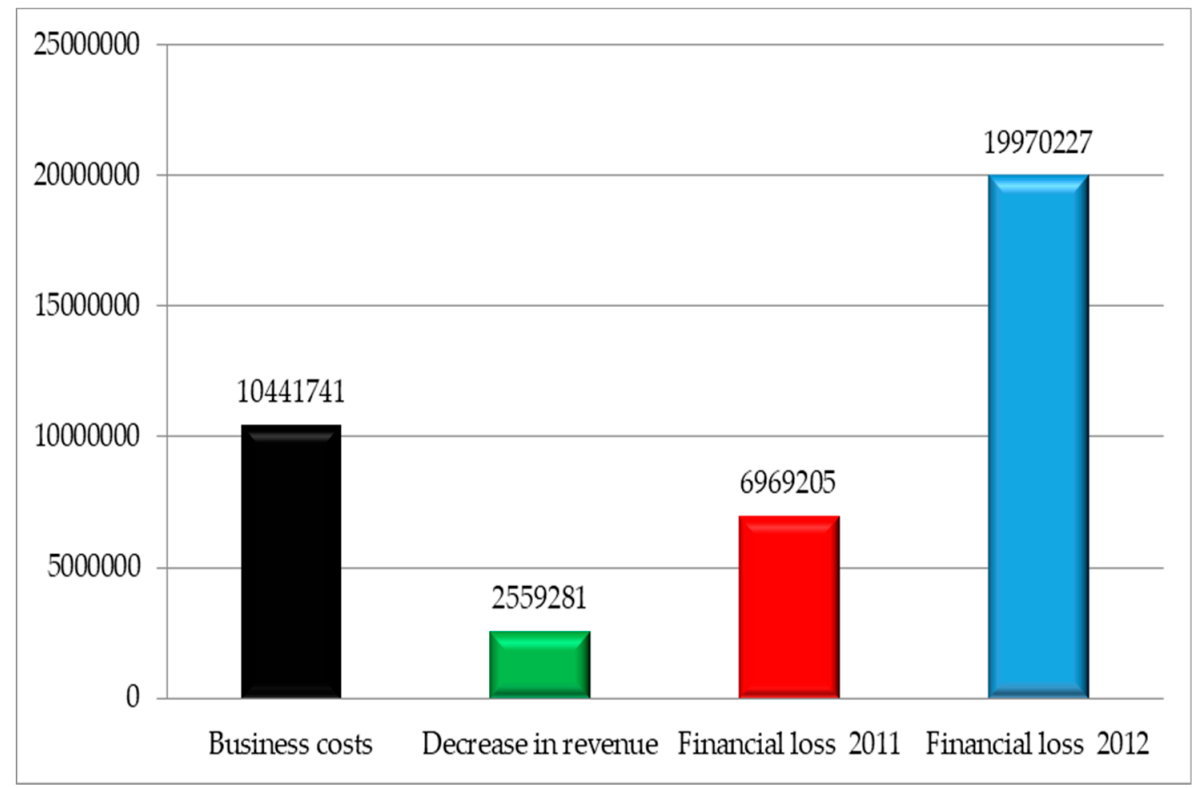

Figure 3. Financial loss of RRS 2011-2012. 


\subsection{Problem Identification and Solving Methodology}

The analysis of the passenger traffic subsystem showed the following characteristics: From 1996 until today, the number of passengers has been in constant decline, the number of passenger trains has decreased in domestic traffic by 28 trains, in inter-entity transport by 18 trains, and by 8 trains in international transport. The railway fee for the infrastructure in domestic services amounts to $4,176,295 \mathrm{KM}$, in inter-entity transport amounts to $601,836 \mathrm{KM}$, and in international transport amounts to 1,603,022 KM. The other elements of the RRS business operations are shown in [36]. The problem-solving methodology is based on:

1. increase in revenue from direct ticket sales and increase in revenue from agreements on PSO,

2. reduction in expensing, i.e., operating costs.

The expected result of the mentioned activities according to the given methodology should be sustainable business operations. Figure 4 shows the cost realization plan for the next fiscal year, as well as the perception of cost coverage by government revenues and government subsidies (PSOs), and a model of the long-term business stabilization goal (Figure 5).

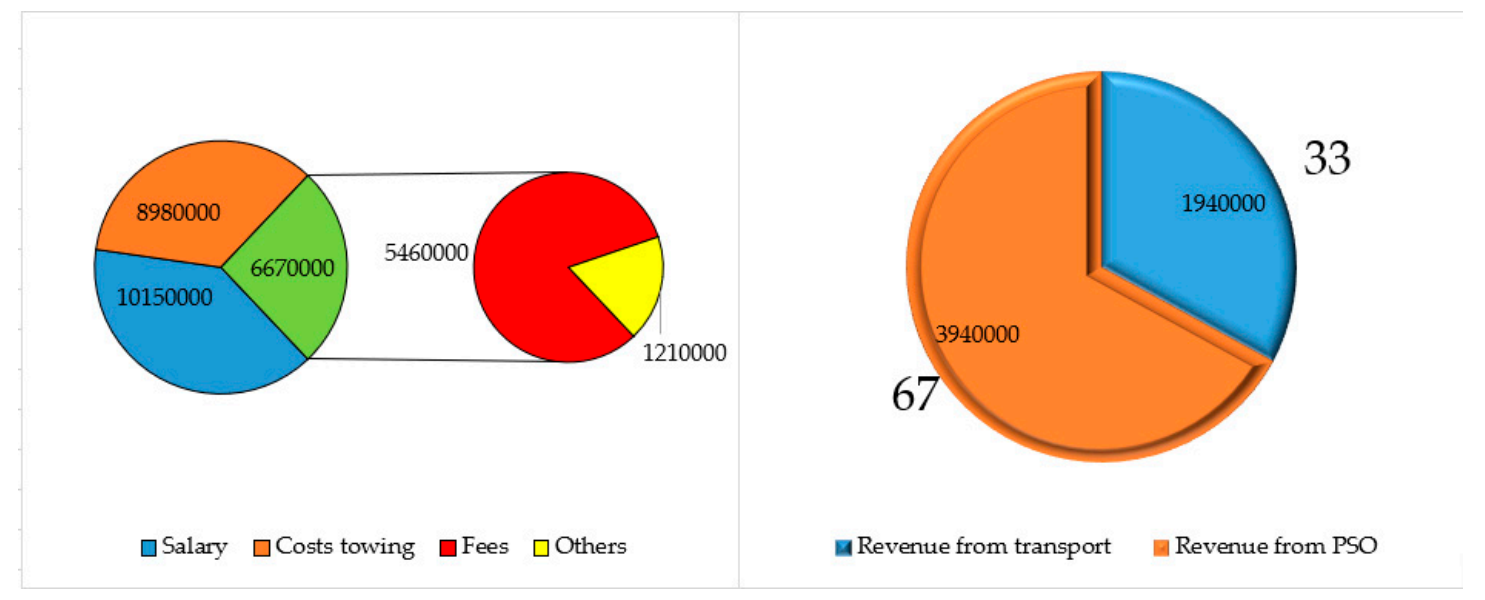

Figure 4. Business plan for the period of 2013 year (costs and revenue).

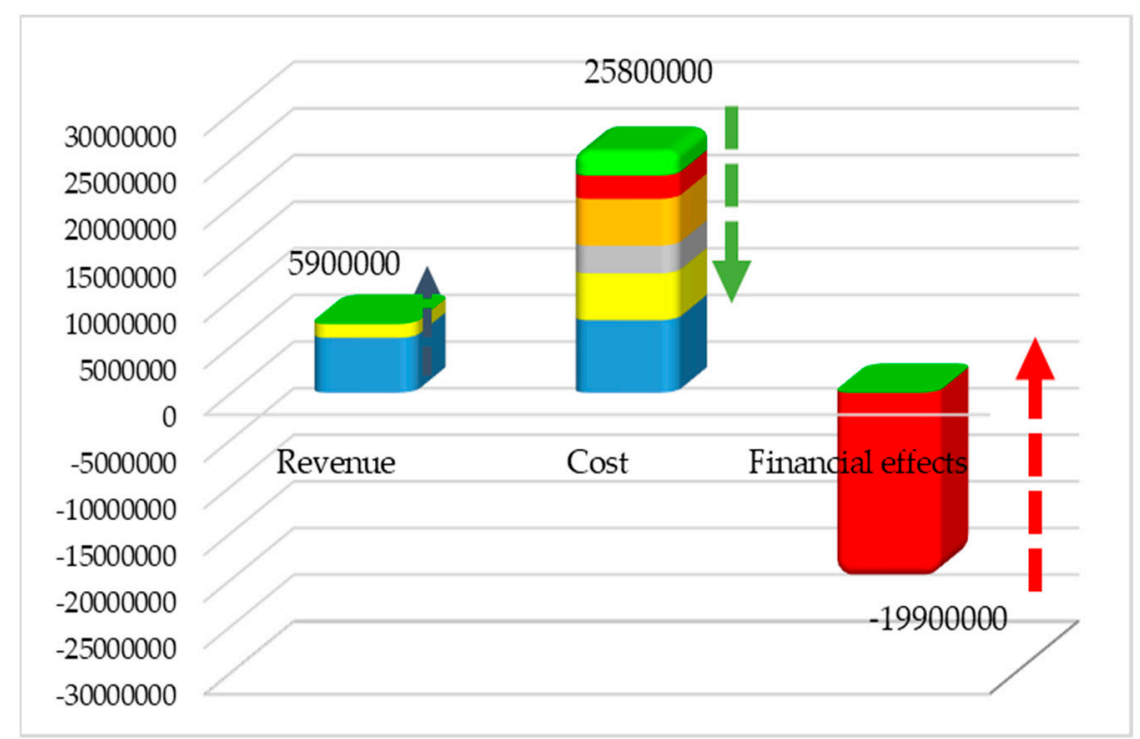

Figure 5. Problem-solving methodology. 
The aim of the problem solving is to bring RRS as the operator in passenger traffic into the domain of positive operations, thus providing the necessary conditions for successful operation at a liberalized transport market. In [6], details about the model for liberalization in Serbia can be found.

In this paper, a new integrated F-PIPRECIA-F-EDAS model is created for solving problems. Multi-criteria methods for decision-making are used to resolve a large number of problems in all spheres of business, and they represent an area that is developing rapidly, primarily due to a large number of methods that have been developed, particularly within the last decade. The combination of these methods with fuzzy logic gives excellent results because classical methods cannot, with such precision, perform the required quantification, and this is where fuzzy logic shows all its advantages $[37,38]$.

\subsection{Forming a MCDM Model}

\subsubsection{Possible Solutions}

In order to resolve the problem, seven realistically possible variants (V) have been identified. All variants are described in [36]:

V1: Reduction in operating costs (Figure 6 left):

$$
T=f\left(T_{1}, T_{2}, T_{3}, \ldots, T_{n}\right) \rightarrow \min
$$

where $T$ denotes costs.

V2: Increase in revenue from ticket sales (Figure 6 right):

$$
P_{1}=f\left(P_{11}, P_{12}, P_{13}, \ldots, P_{1 n}\right) \rightarrow \max
$$

where $P$ denotes revenue.

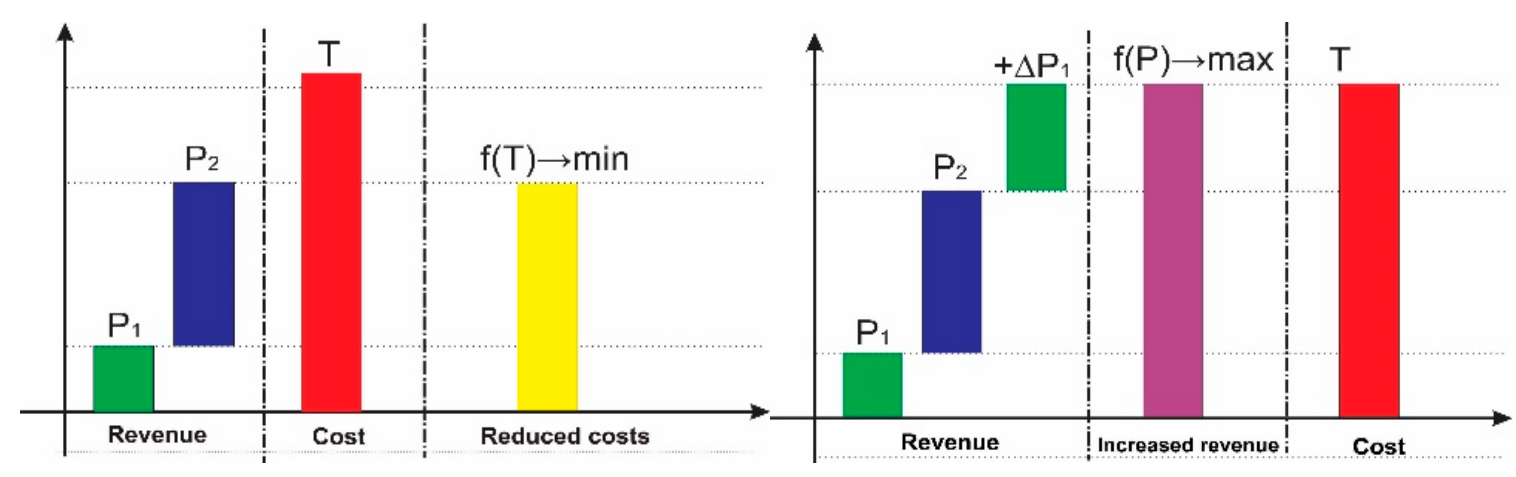

Figure 6. V1-reduction in operating costs, V2-increase in revenue from ticket sales.

V3: Increase in ticket revenue and reduction in operating costs (Figure 7 left):

$$
P_{1}=f\left(P_{11}, P_{12}, P_{13}, \ldots, P_{1 n}\right) \rightarrow \max . \wedge T=f\left(T_{1}, T_{2}, T_{3}, \ldots, T_{n}\right) \rightarrow \min
$$

V4: Increase in revenue from PSO services (Figure 7 right):

$$
P_{2}=f\left(P_{21}, P_{22}, P_{23}, \ldots, P_{1 n}\right) \rightarrow \max
$$




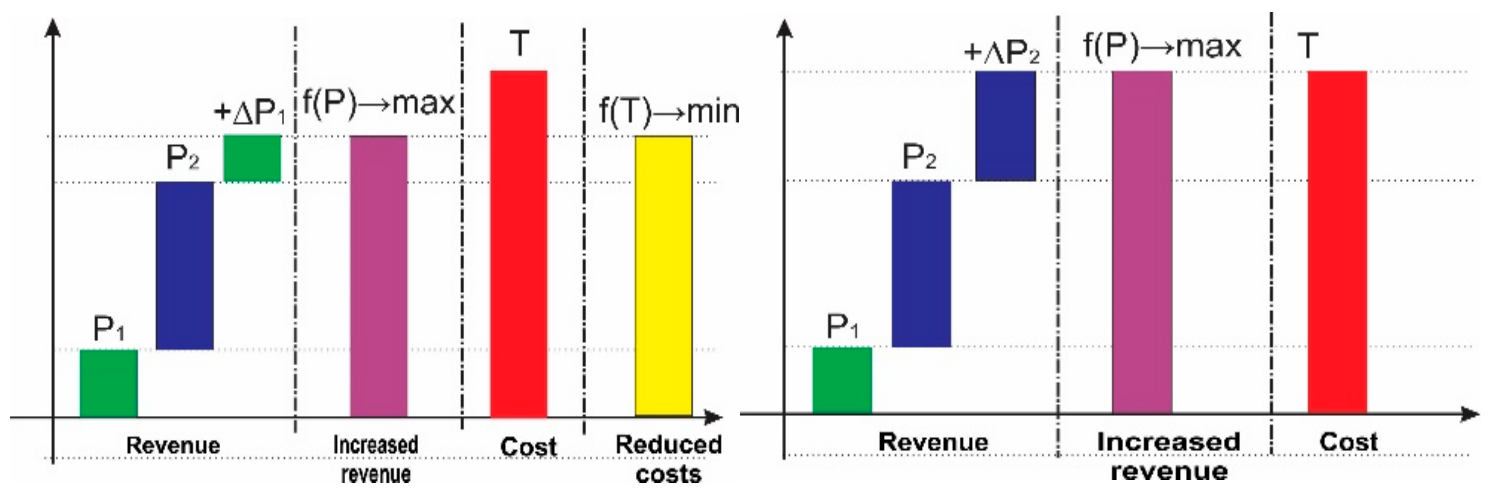

Figure 7. V3-increase in ticket revenue and reduction in operating costs, V4-increase in revenue from Public Service Obligation (PSO) services.

V5: Increase in revenue from PSO services and reduction in operating costs (Figure 8 left):

$$
P_{2}=f\left(P_{21}, P_{22}, P_{23}, \ldots, P_{2 n}\right) \rightarrow \max . \wedge T=f\left(T_{1}, T_{2}, T_{3}, \ldots, T_{n}\right) \rightarrow \min
$$

V6: Increase in revenue from ticket sales and PSO services (Figure 8 right):

$$
P_{1}+P_{2}=f\left(P_{11}, P_{12}, P_{13}, \ldots, P_{1 n}\right)+=f\left(P_{21}, P_{22}, P_{23}, \ldots, P_{2 n}\right) \rightarrow \max
$$

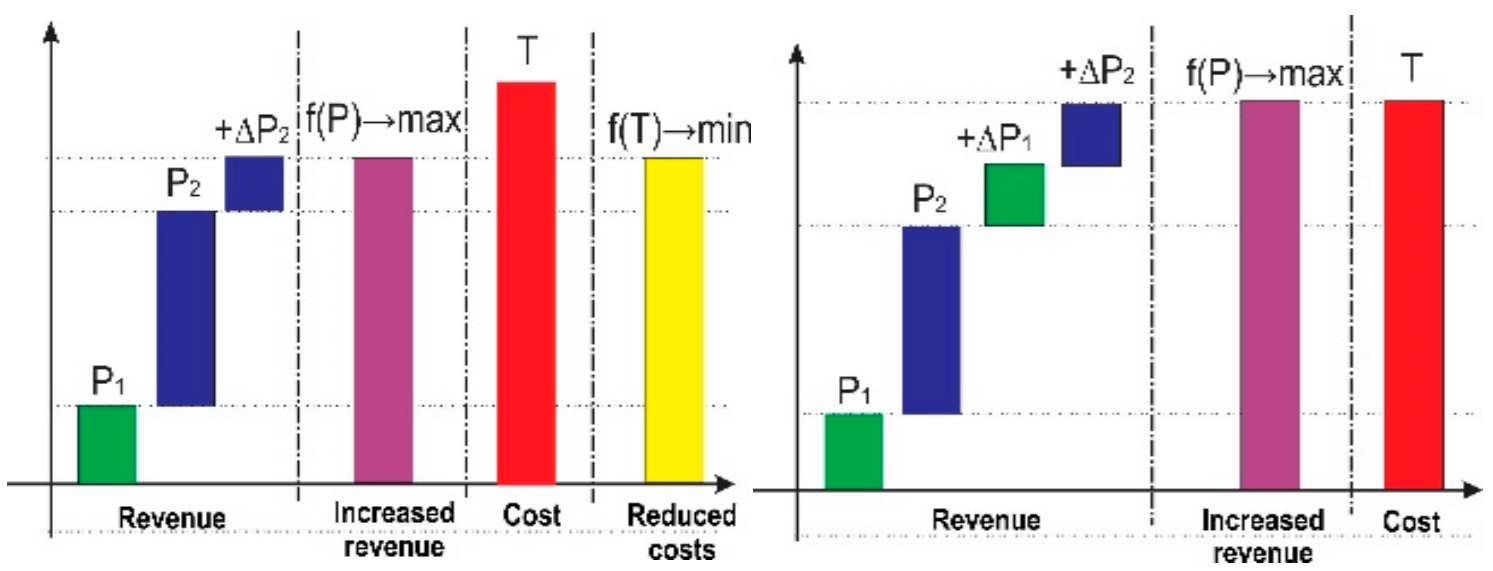

Figure 8. V5-increase in revenue from PSO services and reduction in operating costs, V6-increase in revenue from ticket sales and PSO services.

V7: Increase in revenue from ticket sales and PSO services and reduction in costs (Figure 9):

$$
P_{1}+P_{2}=f\left(P_{11}, P_{12}, P_{13}, \ldots, P_{1 n}\right)+=f\left(P_{21}, P_{22}, P_{23}, \ldots, P_{2 n}\right) \rightarrow \max
$$




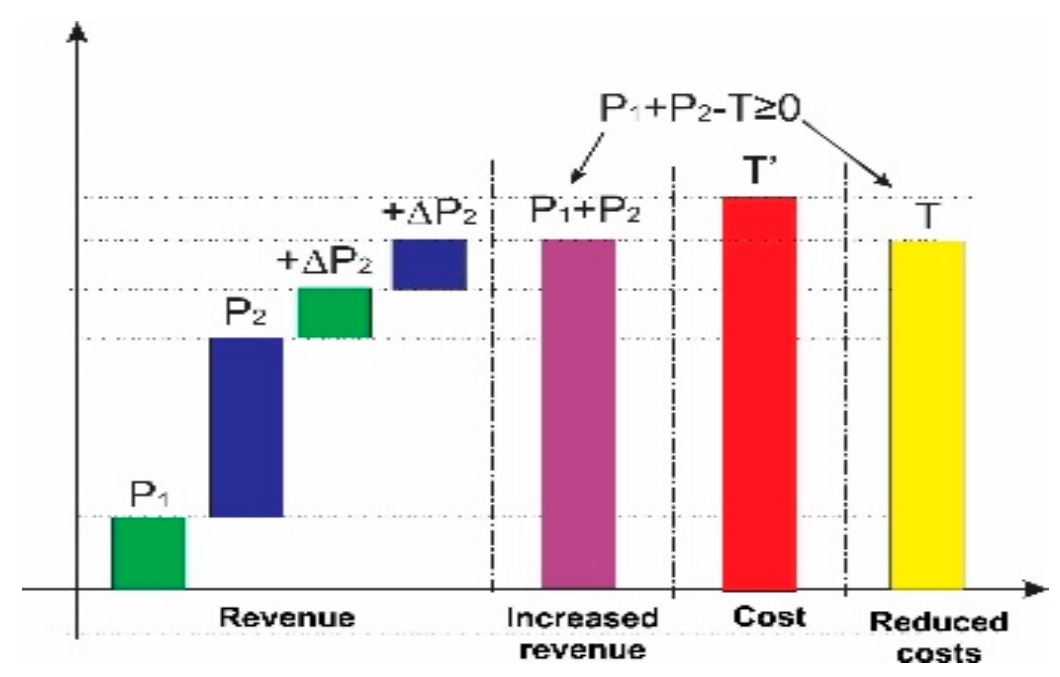

Figure 9. V7-increase in revenue from ticket sales and PSO services and reduction in costs.

\subsubsection{Identification of Evaluation Criteria}

Identification and quantification of the criteria for evaluating the manner of implementing the principles and concluding a PSO contract were carried out over four steps: Defining the required level or volume of service, reduction in business costs, increase in revenues from ticket sales, and increase in revenues under the PSO contract.

The selection of an optimal variant depends on many factors. Therefore, in the proposed methodology, as the criteria, the following values have been adopted: The reality of the feasibility of the proposed variant, means available to the public authority - budget, the ability of the operator, the effect of realization, and the period of realization (Table 1).

Table 1. Criteria for evaluation of identified variants.

\begin{tabular}{ccc}
\hline Mark & Title of Criterion & Type \\
\hline$C_{1}$ & variant feasibility & profit-type \\
$C_{2}$ & public authorities-the budget size & profit-type \\
$C_{3}$ & operators' ability & profit-type \\
$C_{4}$ & the effect of realization & profit-type \\
$C_{5}$ & Period of realization & loss-type \\
\hline
\end{tabular}

\section{Results}

As for obtaining the weight value of criteria, we have used the F-PIPRECIA method; after identifying the criteria on which the ranking of potential variants will be made, it is required that we compare the criteria by using the scale presented in [17]. In order to derive the relative importance of the criteria, a team of three experts had been established; for many years, they have been performing managerial functions in the field of railway transport. As this is an already exploited method, detailed procedures for calculating the values of criteria will not be shown, but rather the summed results by each step (Table 2). 
Table 2. Calculation and results of applying the fuzzy PIvot Pairwise RElative Criteria Importance Assessment (F-PIPRECIA) method for determining the criteria weights.

\begin{tabular}{|c|c|c|c|c|c|}
\hline & $\overline{s_{j}}$ & $\overline{k_{j}}$ & $\overline{q_{j}}$ & $\overline{w_{j}}$ & $\mathrm{DF}$ \\
\hline $\mathrm{C} 1$ & & $(1,1,1)$ & $(1,1,1)$ & $(0.288,0.323,0.364)$ & 0.324 \\
\hline $\mathrm{C} 2$ & $(0.356,0.433,0.556)$ & $(1.444,1.567,1.644)$ & $(0.608,0.638,0.692)$ & $(0.175,0.206,0.252)$ & 0.209 \\
\hline $\mathrm{C} 3$ & $(0.262,0.302,0.356)$ & $(1.644,1.698,1.738)$ & $(0.35,0.376,0.421)$ & $(0.101,0.121,0.153)$ & 0.123 \\
\hline $\mathrm{C} 4$ & $(1.3,1.45,1.5)$ & $(0.5,0.55,0.7)$ & $(0.5,0.683,0.842)$ & $(0.144,0.22,0.307)$ & 0.222 \\
\hline C5 & $(0.262,0.302,0.356)$ & $(1.644,1.698,1.738)$ & $(0.288,0.402,0.512)$ & $(0.083,0.13,0.187)$ & 0.131 \\
\hline \multirow[t]{2}{*}{ SUM } & & & $(2.745,3.1,3.467)$ & & \\
\hline & $\overline{s_{j}^{\prime}}$ & $\overline{k_{j}^{\prime}}$ & $\overline{q_{j}^{\prime}}$ & $\overline{w_{j}^{\prime}}$ & DF \\
\hline $\mathrm{C} 1$ & $(1.333,1.5,1.55)$ & $(0.45,0.5,0.667)$ & $(2.276,7.36,11.54)$ & $(0.088,0.399,1.45)$ & 0.523 \\
\hline $\mathrm{C} 2$ & $(1.233,1.35,1.4)$ & $(0.6,0.65,0.767)$ & $(1.517,3.68,5.193)$ & $(0.059,0.2,0.653)$ & 0.252 \\
\hline $\mathrm{C} 3$ & $(0.28,0.328,0.395)$ & $(1.605,1.672,1.72)$ & $(1.163,2.392,3.116)$ & $(0.045,0.13,0.392)$ & 0.159 \\
\hline $\mathrm{C} 4$ & $(1.5,1.75,1.8)$ & $(0.2,0.25,0.5)$ & $(2,4,5)$ & $(0.077,0.217,0.628)$ & 0.262 \\
\hline $\mathrm{C} 5$ & & $(1,1,1)$ & $(1,1,1)$ & $(0.039,0.054,0.126)$ & 0.064 \\
\hline SUM & & & $(7.956,18.432,25.848$ & & \\
\hline
\end{tabular}

Where $\overline{s_{j}}$ represents the group matrix obtained by expert's assessment, starting from the second criterion, and $\overline{k_{j}}$ is the coefficient obtained when $\overline{s_{j}}$ is subtracted from number 2, except for $\overline{s_{1}} \cdot \overline{q_{j}}$ is the fuzzy weight, $\frac{j}{w_{j}}$ is the relative weight of the criterion, and DF is the defuzzified value.

Based on the aggregation of the values wj shown in Table 2, the final criterion values are obtained: $w_{1}=0.423 ; w_{2}=0.230 ; w_{3}=0.141 ; w_{4}=0.242 ; w_{5}=0.098$. After calculating the weight value of criteria, we then begin the selection of the optimal variant by using the F-EDAS method. On the basis of the linguistic scale, the experts evaluate variants according to each criterion individually (Table 3).

Table 3. Evaluation of variants according to the criteria expressed in trapezoidal fuzzy numbers.

\begin{tabular}{|c|c|c|c|c|c|c|}
\hline \multirow{2}{*}{ Expert Rating } & \multirow{2}{*}{ Variant } & \multicolumn{5}{|c|}{ Criterion } \\
\hline & & $C_{1}$ & $C_{2}$ & $C_{3}$ & $\mathrm{C}_{4}$ & $\mathrm{C}_{5}$ \\
\hline \multirow{7}{*}{$E_{1}$} & $\mathrm{~V}_{1}$ & $(1,2,2,3)$ & $(4,5,5,6)$ & $(8,9,10,10)$ & $(8,9,10,10)$ & $(0,0,1,2)$ \\
\hline & $\mathrm{V}_{2}$ & $(0,0,1,2)$ & $(5,6,7,8)$ & $(8,9,10,10)$ & $(5,6,7,8)$ & $(0,0,1,2)$ \\
\hline & $\mathrm{V}_{3}$ & $(2,3,4,5)$ & $(5,6,7,8)$ & $(7,8,8,9)$ & $(8,9,10,10)$ & $(5,6,7,8)$ \\
\hline & $\mathrm{V}_{4}$ & $(1,2,2,3)$ & $(8,9,10,10)$ & $(4,5,5,6)$ & $(7,8,8,9)$ & $(0,0,1,2)$ \\
\hline & $\mathrm{V}_{5}$ & $(5,6,7,8)$ & $(7,8,8,9)$ & $(7,8,8,9)$ & $(7,8,8,9)$ & $(7,8,8,9)$ \\
\hline & $\mathrm{V}_{6}$ & $(7,8,8,9)$ & $(7,8,8,9)$ & $(7,8,8,9)$ & $(8,9,10,10)$ & $(5,6,7,8)$ \\
\hline & $\mathrm{V}_{7}$ & $(8,9,10,10)$ & $(7,8,8,9)$ & $(5,6,7,8)$ & $(8,9,10,10)$ & $(7,8,8,9)$ \\
\hline \multirow{7}{*}{$E_{2}$} & $\mathrm{~V}_{1}$ & $(2,3,4,5)$ & $(5,6,7,8)$ & $(8,9,10,10)$ & $(7,8,8,9)$ & $(1,2,2,3)$ \\
\hline & $\mathrm{V}_{2}$ & $(1,2,2,3)$ & $(7,8,8,9)$ & $(8,9,10,10)$ & $(7,8,8,9)$ & $(0,0,1,2)$ \\
\hline & $\mathrm{V}_{3}$ & $(4,5,5,6)$ & $(7,8,8,9)$ & $(8,9,10,10)$ & $(8,9,10,10)$ & $(5,6,7,8)$ \\
\hline & $\mathrm{V}_{4}$ & $(2,3,4,5)$ & $(8,9,10,10)$ & $(4,5,5,6)$ & $(8,9,10,10)$ & $(0,0,1,2)$ \\
\hline & $\mathrm{V}_{5}$ & $(5,6,7,8)$ & $(8,9,10,10)$ & $(7,8,8,9)$ & $(7,8,8,9)$ & $(5,6,7,8)$ \\
\hline & $\mathrm{V}_{6}$ & $(7,8,8,9)$ & $(7,8,8,9)$ & $(8,9,10,10)$ & $(7,8,8,9)$ & $(7,8,8,9)$ \\
\hline & $\mathrm{V}_{7}$ & $(8,9,10,10)$ & $(7,8,8,9)$ & $(7,8,8,9)$ & $(8,9,10,10)$ & $(8,9,10,10)$ \\
\hline \multirow{7}{*}{$E_{3}$} & $\mathrm{~V}_{1}$ & $(1,2,2,3)$ & $(4,5,5,6)$ & $(8,9,10,10)$ & $(7,8,8,9)$ & $(0,0,1,2)$ \\
\hline & $\mathrm{V}_{2}$ & $(0,0,1,2)$ & $(5,6,7,8)$ & $(7,8,8,9)$ & $(8,9,10,10)$ & $(0,0,1,2)$ \\
\hline & $\mathrm{V}_{3}$ & $(4,5,5,6)$ & $(7,8,8,9)$ & $(8,9,10,10)$ & $(8,9,10,10)$ & $(7,8,8,9)$ \\
\hline & $\mathrm{V}_{4}$ & $(0,0,1,2)$ & $(7,8,8,9)$ & $(4,5,5,6)$ & $(7,8,8,9)$ & $(1,2,2,3)$ \\
\hline & $\mathrm{V}_{5}$ & $(7,8,8,9)$ & $(8,9,10,10)$ & $(7,8,8,9)$ & $(8,9,10,10)$ & $(7,8,8,9)$ \\
\hline & $\mathrm{V}_{6}$ & $(5,6,7,8)$ & $(8,9,10,10)$ & $(8,9,10,10)$ & $(7,8,8,9)$ & $(7,8,8,9)$ \\
\hline & $\mathrm{V}_{7}$ & $(7,8,8,9)$ & $(7,8,8,9)$ & $(5,6,7,8)$ & $(8,9,10,10)$ & $(8,9,10,10)$ \\
\hline
\end{tabular}


Table 4 also shows, apart from the values of the average decision matrix, the values of an average solution according to all the criteria.

Table 4. The elements of the average decision-matrix and the average solution matrix.

\begin{tabular}{ccccc}
\hline & $\mathbf{V}_{\mathbf{1}}$ & $\mathbf{V}_{\mathbf{2}}$ & $\mathbf{V}_{\mathbf{3}}$ & $\mathbf{V}_{\mathbf{4}}$ \\
\cline { 2 - 5 } $\mathbf{C}_{\mathbf{1}}$ & $(0.13,0.23,0.27,0.37)$ & $(0.03,0.07,0.13,0.23)$ & $(0.33,0.43,0.47,0.57)$ & $(0.1,0.17,0.23,0.33)$ \\
$\mathbf{C}_{\mathbf{2}}$ & $(0.43,0.53,0.57,0.67)$ & $(0.57,0.67,0.73,0.83)$ & $(0.63,0.73,0.77,0.87)$ & $(0.77,0.87,0.93,0.97)$ \\
$\mathbf{C}_{\mathbf{3}}$ & $(0.8,0.9,1.0,1.0)$ & $(0.77,0.87,0.93,0.97)$ & $(0.77,0.87,0.93,0.97)$ & $(0.4,0.5,0.5,0.6)$ \\
$\mathbf{C}_{\mathbf{4}}$ & $(0.73,0.83,0.87,0.93$ & $(0.67,0.77,0.83,0.9)$ & $(0.8,0.9,1.0,1.0)$ & $(0.73,0.83,0.87,0.93$ \\
$\mathbf{C}_{\mathbf{5}}$ & $(0.03,0.07,0.13,0.23)$ & $(0,0,0.1,0.2)$ & $(0.57,0.67,0.73,0.83)$ & $(0.03,0.07,0.13,0.23)$ \\
\hline & $\mathrm{V}_{5}$ & $\mathrm{~V}_{6}$ & $\mathrm{~V}_{7}$ & $\mathrm{AV}$ \\
\hline $\mathbf{C}_{\mathbf{1}}$ & $(0.57,0.67,0.73,0.83)$ & $(0.63,0.73,0.77,0.87)$ & $(0.77,0.87,0.93,0.97)$ & $(0.37,0.45,0.50,0.60)$ \\
$\mathbf{C}_{\mathbf{2}}$ & $(0.77,0.87,0.93,0.97)$ & $(0.73,0.83,0.87,0.93$ & $(0.7,0.8,0.8,0.9)$ & $(0.66,0.76,0.80,0,88)$ \\
$\mathbf{C}_{\mathbf{3}}$ & $(0.7,0.8,0.8,0.9)$ & $(0.77,0.87,0.93,0.97)$ & $(0.57,0.67,0.73,0.83)$ & $(0.68,0.78,0.83,0.89)$ \\
$\mathbf{C}_{\mathbf{4}}$ & $(0.73,0.83,0.87,0.93)$ & $(0.73,0.83,0.87,0.93)$ & $(0.8,0.9,1.0,1.0)$ & $(0.74,0.84,0.90,0.95)$ \\
$\mathbf{C}_{\mathbf{5}}$ & $(0.63,0.73,0.77,0.87)$ & $(0.63,0.73,0.77,0.87)$ & $(0.77,0.87,0.93,0.97)$ & $(0.38,0.45,0.51,0.60)$ \\
\hline
\end{tabular}

Next, we need to calculate positive distances (PDA) and negative distances (NDA) from the average solutions depending on the criteria type. In this case, only the fifth criterion is useless, while the others are useful criteria. First, we obtain the values of the positive distance (PDA) and the values of the negative distance from the average solution. In order to obtain the values shown in Table 5 , it is necessary to first apply step 5 of the F-EDAS method, and this represents the sum of the weighted matrix for positive $\widetilde{s p_{i}}$ and negative distance $\widetilde{s n}_{i}$ for all variants. Further, it is necessary to normalize previous values in order to obtain $\widetilde{n s p}$ and $\widetilde{n s n_{i}}$. Finally, it is necessary to calculate the assessment of the results, the appraisal score $\left(\widetilde{a s}_{i}\right)$, and make the defuzzification appraisal score $\left(\widetilde{a s}_{i}\right)$ (Table 5).

Table 5. The weighted sum of distances, the normalized values of them, and the appraisal scores.

\begin{tabular}{ccccc}
\hline & $\widetilde{s p}_{i}$ & ${\widetilde{s n_{i}}}_{\boldsymbol{i}}$ & $\widetilde{n s p}_{\boldsymbol{i}}$ \\
\hline $\mathbf{V}_{\mathbf{1}}$ & $(0.01,0.08,0.13,0.17)$ & $(-0.06,0.21,0.34,0.61)$ & $(0.04,0.20,0.33,0.45)$ \\
$\mathbf{V}_{\mathbf{2}}$ & $(0.01,0.08,0.13,0.17)$ & $(0.02,0.30,0.46,0.67)$ & $(0.04,0.20,0.34,0.45)$ \\
$\mathbf{V}_{\mathbf{3}}$ & $(-0.06,0.01,0.07,0.12)$ & $(-0.25,-0.01,0.14,0.40)$ & $(-0.16,0.02,0.19,0.33)$ \\
$\mathbf{V}_{\mathbf{4}}$ & $(0.00,0.08,0.14,0.21)$ & $(-0.01,0.24,0.37,0.59)$ & $(0.00,0.22,0.37,0.54)$ \\
$\mathbf{V}_{\mathbf{5}}$ & $(-0.09,0.16,0.30,0.54)$ & $(-0.05,0.04,0.08,0.16)$ & $(-0.23,0.42,0.78,1.42)$ \\
$\mathbf{V}_{\mathbf{6}}$ & $(-0.04,0.21,0.34,0.58)$ & $(-0.05,0.04,0.08,0.16)$ & $(-0.09,0.56,0.89,1.51)$ \\
$\mathbf{V}_{\mathbf{7}}$ & $(0.06,0.32,0.48,0.68)$ & $(0.01,0.08,0.13,0.18)$ & $(0.16,0.84,1.25,1.78)$ \\
\hline & $\widetilde{n s n_{i}}$ & $\widetilde{a s_{i}}$ & $\mathrm{k}\left(\widetilde{\left.a s_{i}\right)}\right.$ & Rank \\
\hline $\mathbf{V}_{\mathbf{1}}$ & $(-0.69,0.04,0.42,1.17)$ & $(-0.33,0.12,0.37,0.81)$ & 0.244 & 5 \\
$\mathbf{V}_{\mathbf{2}}$ & $(-0.86,-0.28,0.17,0.94)$ & $(-0.41,-0.04,0.26,0.69)$ & 0.127 & 7 \\
$\mathbf{V}_{\mathbf{3}}$ & $(-0.11,0.60,0.96,1.70)$ & $(-0.14,0.31,0.57,1.01)$ & 0.439 & 4 \\
$\mathbf{V}_{\mathbf{4}}$ & $(-0.63,-0.04,0.33,1.02)$ & $(-0.32,0.09,0.35,0.78)$ & 0.227 & 6 \\
$\mathbf{V}_{\mathbf{5}}$ & $(0.56,0.76,0.90,1.13)$ & $(0.16,0.59,0.84,1.28)$ & 0.718 & 3 \\
$\mathbf{V}_{\mathbf{6}}$ & $(0.56,0.76,0.90,1.13)$ & $(0.23 .0 .66,0.89,1.32)$ & 0.778 & 2 \\
$\mathbf{V}_{\mathbf{7}}$ & $(0.51,0.65,0.77,0.98)$ & $(0.33,0.75,1.01,1.38)$ & 0.865 & 1 \\
\hline
\end{tabular}

Based on the performed analysis, and in accordance with the task, implementation of Variant $\mathrm{A}_{7}$ is recommended as the most acceptable solution. As good enough solutions, we might accept variants $A_{6}$ and $A_{5}$; Variant $A_{3}$ could possibly represent a satisfactory solution. Thus, it is evident that the most acceptable variant is essentially the scenario in which the positive result stems from joint "efforts" of the operator (decreased costs and increased revenues from the ticket sales) and public authorities through increased subsidies for PSO. Another acceptable variant is a scenario where, because of the limitations of the market (low flow and low purchasing power of the population-passengers), there 
lacks any significant increase in revenue from ticket sales; the solution is then sought through reduction in costs and increase in PSO subsidies. The variants where the problem is solved only by increased PSO subsidies by the public authorities and the combined approach based on the increase in revenues from ticket sales and operator's cost reduction are not favorable.

\section{Validation Tests}

\subsection{Changing the Significance of Criteria}

In this phase of validation test, the impact of changing the three most important criteria $C_{1}, C_{2}$, and $C_{4}$ on the ranking results was analyzed. Using Equation (8), a total of 18 scenarios were formed.

$$
W_{n \beta}=\left(1-W_{n \alpha}\right) \frac{W_{\beta}}{\left(1-W_{n}\right)}
$$

In scenarios $S_{1}-S_{6}$, the first criterion was changed, criterion $C_{2}$ was changed in scenarios $S_{7}-S_{12}$, and criterion $C_{4}$ was changed in scenarios $S_{13}-S_{18}$. In Equation (8), $\widetilde{W}_{n \beta}$ represents the new value of criteria $C_{2}-C_{5}$ for scenarios $S_{1}-S_{6}$; then, $C_{1}, C_{3}-C_{5}$ for scenarios $S_{7}-S_{12}$, i.e., $C_{1}-C_{3}$, and $C_{5}$ for scenarios $\mathrm{S}_{13}-\mathrm{S}_{18} . \widetilde{W}_{n \alpha}$ represents the corrected value of criteria $\mathrm{C}_{1}, \mathrm{C}_{2}$, and $\mathrm{C}_{3}$ respectively by groups of scenarios, $\widetilde{W}_{\beta}$ represents the original value of the criterion considered, and $\widetilde{W}_{n}$ represents the original value of the criterion whose value is reduced, in this case, $C_{1}, C_{2}$, and $C_{4}$.

In all scenarios, the value of criteria was reduced by $15 \%$, while the values of the remaining criteria were proportionally corrected by applying Equation (8). After forming 18 new vectors of the weight coefficients of the criteria (Table 6), new model results were obtained, as presented in Figure 10.

Table 6. New criterion values across 18 scenarios.

\begin{tabular}{cccccc}
\hline & $\mathbf{w}_{\mathbf{1}}$ & $\mathbf{w}_{\mathbf{2}}$ & $\mathbf{w}_{\mathbf{3}}$ & $\mathbf{w}_{\mathbf{4}}$ & $\mathbf{w}_{\mathbf{5}}$ \\
\hline $\mathbf{S}_{\mathbf{1}}$ & 0.360 & 0.255 & 0.157 & 0.269 & 0.108 \\
$\mathbf{S}_{\mathbf{2}}$ & 0.296 & 0.281 & 0.172 & 0.296 & 0.119 \\
$\mathbf{S}_{\mathbf{3}}$ & 0.233 & 0.306 & 0.188 & 0.322 & 0.130 \\
$\mathbf{S}_{\mathbf{4}}$ & 0.169 & 0.331 & 0.203 & 0.349 & 0.140 \\
$\mathbf{S}_{\mathbf{5}}$ & 0.106 & 0.357 & 0.219 & 0.376 & 0.151 \\
$\mathbf{S}_{\mathbf{6}}$ & 0.042 & 0.382 & 0.235 & 0.402 & 0.162 \\
$\mathbf{S}_{\mathbf{7}}$ & 0.442 & 0.196 & 0.148 & 0.253 & 0.102 \\
$\mathbf{S}_{\mathbf{8}}$ & 0.461 & 0.161 & 0.154 & 0.264 & 0.106 \\
$\mathbf{S}_{\mathbf{9}}$ & 0.480 & 0.127 & 0.160 & 0.275 & 0.111 \\
$\mathbf{S}_{\mathbf{1 0}}$ & 0.499 & 0.092 & 0.167 & 0.286 & 0.115 \\
$\mathbf{S}_{\mathbf{1 1}}$ & 0.518 & 0.058 & 0.173 & 0.297 & 0.119 \\
$\mathbf{S}_{\mathbf{1 2}}$ & 0.537 & 0.023 & 0.179 & 0.307 & 0.124 \\
$\mathbf{S}_{\mathbf{1 3}}$ & 0.444 & 0.241 & 0.148 & 0.206 & 0.102 \\
$\mathbf{S}_{\mathbf{1 4}}$ & 0.464 & 0.252 & 0.155 & 0.170 & 0.107 \\
$\mathbf{S}_{\mathbf{1 5}}$ & 0.484 & 0.263 & 0.162 & 0.133 & 0.112 \\
$\mathbf{S}_{\mathbf{1 6}}$ & 0.504 & 0.274 & 0.168 & 0.097 & 0.116 \\
$\mathbf{S}_{\mathbf{1 7}}$ & 0.525 & 0.285 & 0.175 & 0.061 & 0.121 \\
$\mathbf{S}_{\mathbf{1 8}}$ & 0.545 & 0.296 & 0.182 & 0.024 & 0.126 \\
\hline
\end{tabular}

In most scenarios, there is no change in initial rank, as shown in Figure 10. However, it is important to emphasize that the model is very sensitive to the change in the most important criterion, and in scenarios S1-S6, significant changes occur. With a slight decrease in the value of the first criterion, the ranks slightly change; for example, variants $V_{1}$ and $V_{4}$ change their positions in the second scenario. As the value of the first criterion decreases drastically, the ranks also change drastically. In the fourth scenario, $V_{7}$ loses the first position, while in the sixth scenario, it comes in last place. Practically, the most important role is played by the first criterion in the set decision conditions. In accordance with 
the rank changes in the mentioned scenarios, a statistical check of the rank correlation was performed using Spearman's correlation coefficient, as shown in Figure 11.

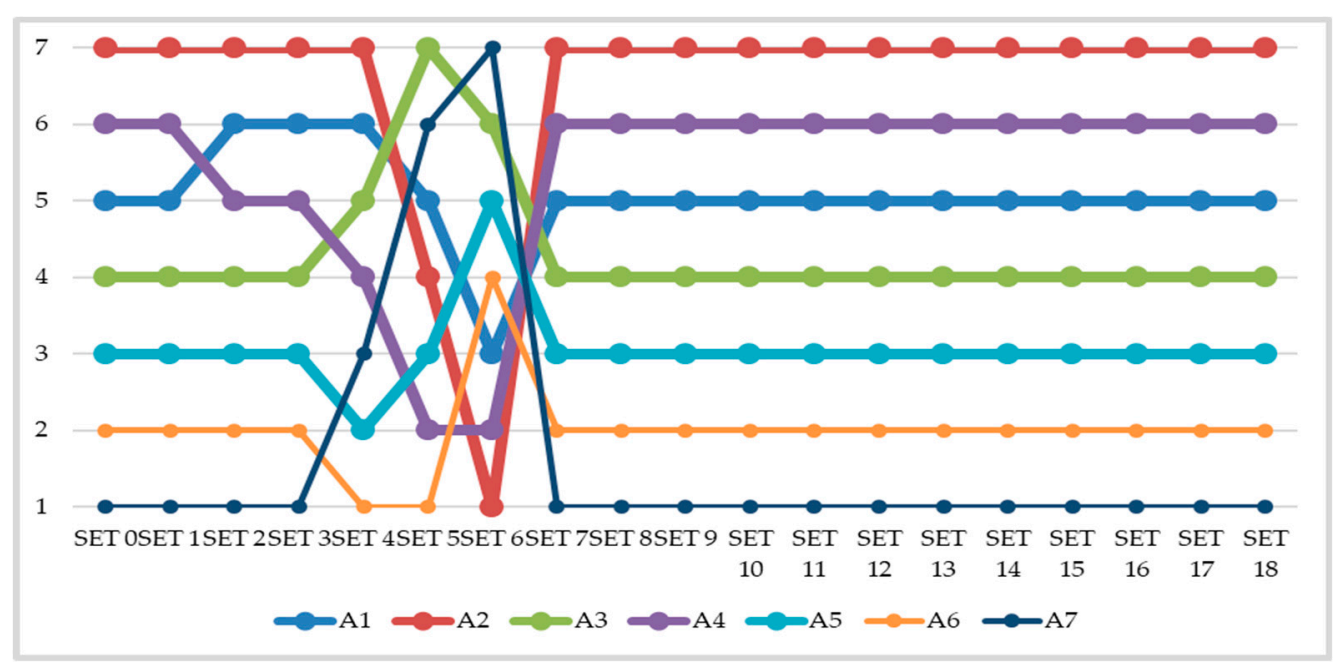

Figure 10. Comparison of obtained results by F-PIPRECIA-Fuzzy Evaluation based on Distance from Average Solution (F-EDAS) model with all formed scenarios S1-S18.

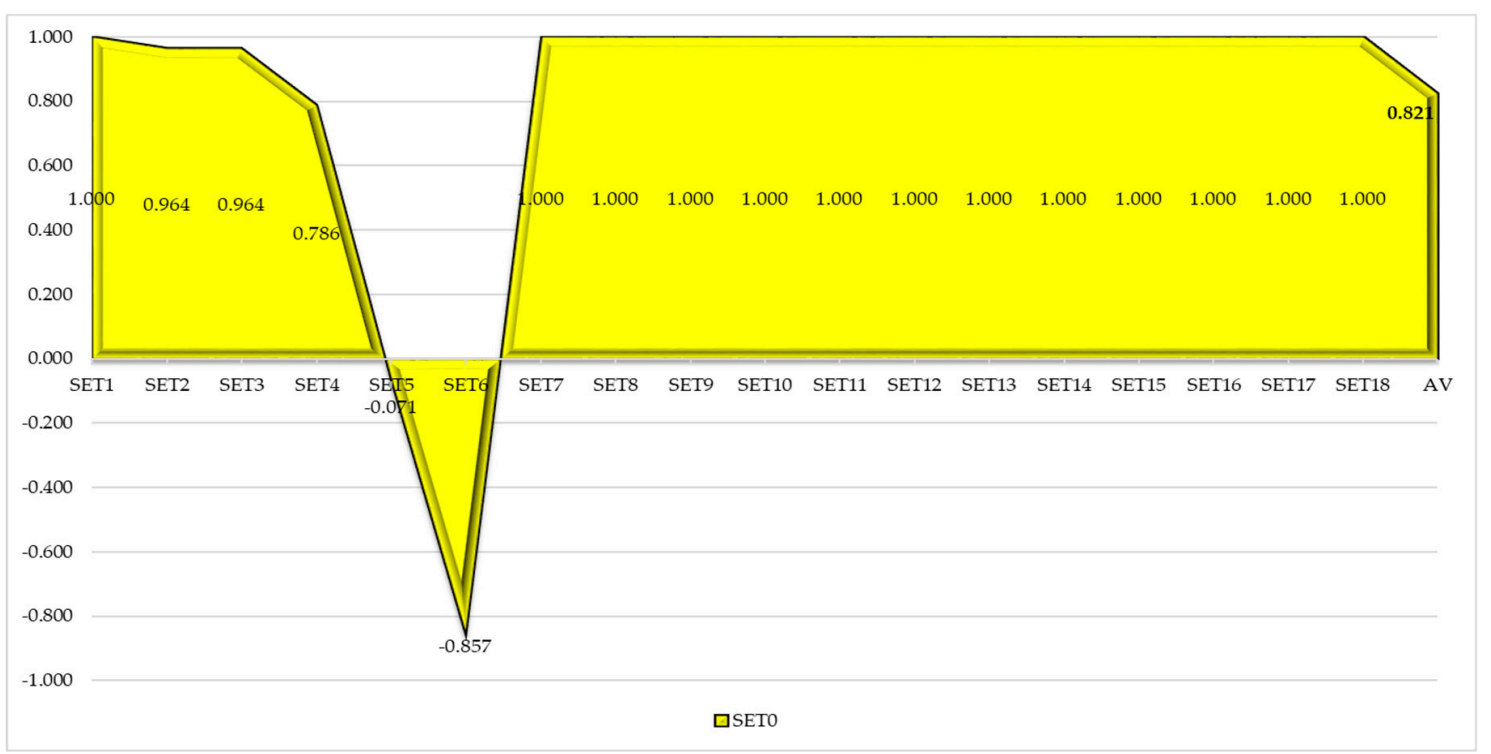

Figure 11. Spearman's correlation coefficient (SCC) through 18 formed scenarios.

The calculated Spearman's correlation coefficient (Figure 11), despite significant deviations in some scenarios, shows a high correlation of ranks in total, 0.821 . Generally, in 13 out of 18 scenarios, variants have a full correlation. The correlation between the initial results obtained by the F-PIPRECIA-F-EDAS model and the $S_{2}$ and $S_{3}$ scenarios is 0.964 , while in the $S_{4}$ scenario, it is 0.786 . The biggest deviation in the rankings is in the fifth and sixth scenarios when the negative correlations are -0.071 and -0.857 , respectively.

\subsection{Impact of Reverse Rank Matrices}

One of the ways to test the validity of the obtained results is to construct dynamic matrices that analyze the solutions that the model provides under new conditions. A change in the number of variants is made for each scenario, eliminating the worst variant from further consideration. In the test, six scenarios are formed in which the change in elements of the decision matrix is simulated. 
As can be seen in Figure 12, there is no change in ranks for any variant. That means that the proposed F-PIPRECIA-F-EDAS model is stable and gives good results.

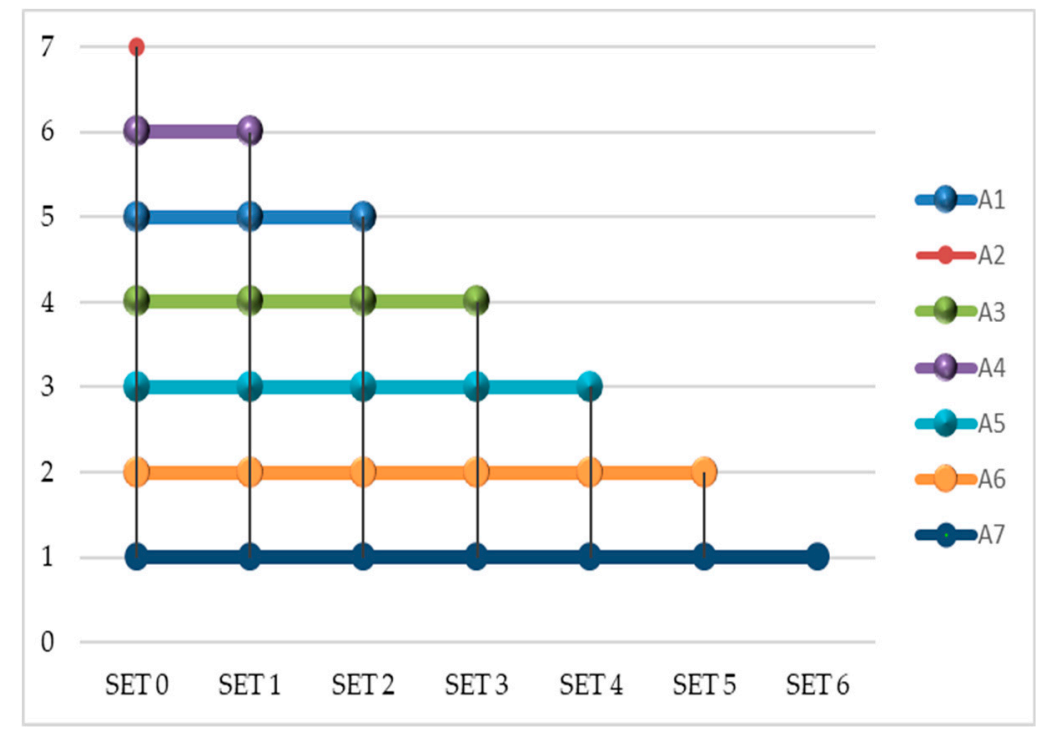

Figure 12. Results of the test of reverse rank matrix.

\subsection{Comparison with other Fuzzy MCDM Methods}

In this part, a validation test is performed, including comparison with three other fuzzy methods: F-MARCOS, F-SAW, and the F-TOPSIS method. Obtained results are presented in Figure 13.

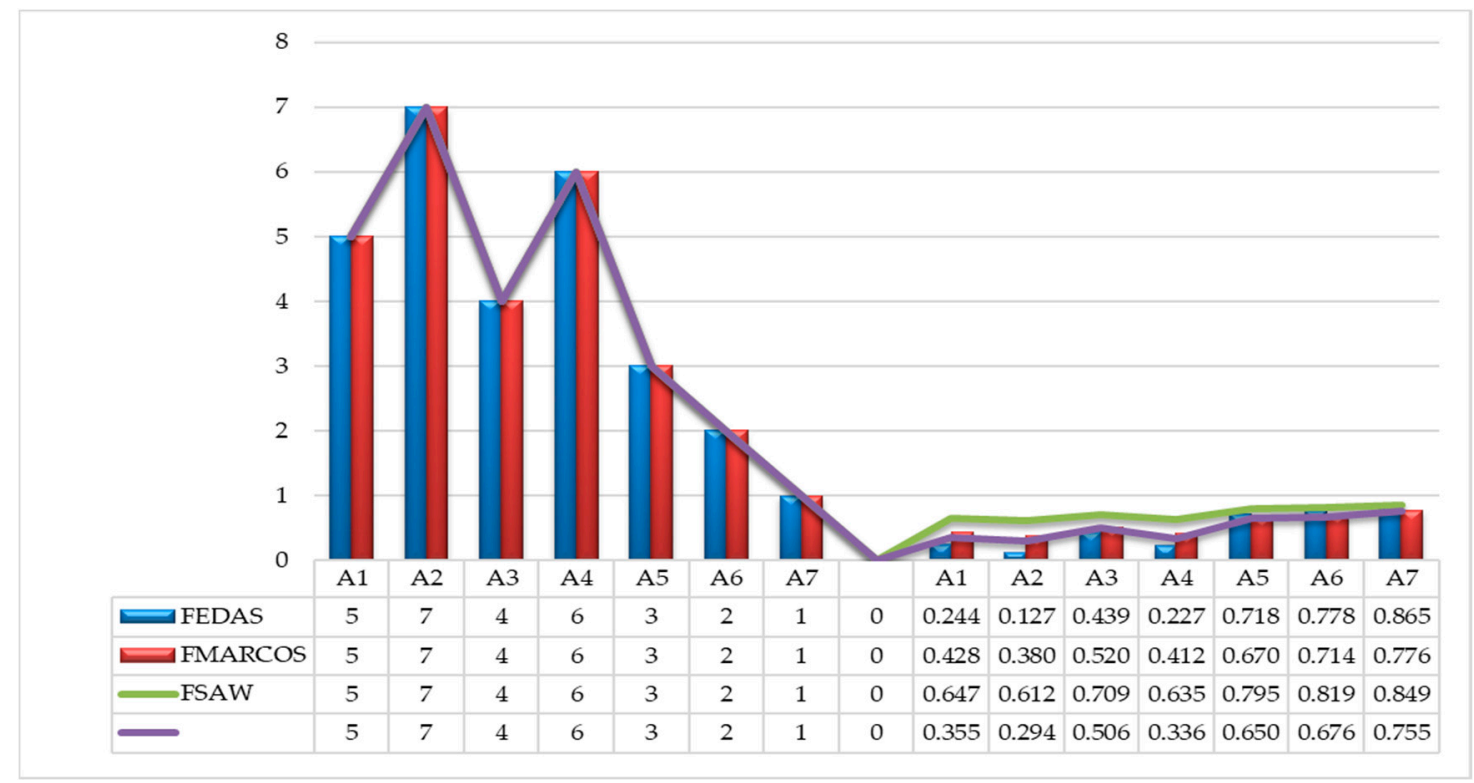

Figure 13. Results of comparison with fuzzy Measurement Alternatives and Ranking according to the COmpromise Solution (F-MARCOS), fuzzy Simple Additive Weighing (F-SAW), and fuzzy Technique for Order of Preference by Similarity to Ideal Solution (F-TOPSIS) methods.

As can be seen in Figure 13, there is no change in ranks for any variant. In Figure 13, in addition to the rankings of variants, values for each variant are given so that a cross-sectional comparison can be made. 


\subsection{Determining Criteria Weights with F-AHP and FUCOM Methods}

In this part of the paper, the criteria weights were re-determined using the F-AHP and FUCOM methods, and the results compared to the original F-PIPRECIA-F-EDAS model are shown in Figure 14.

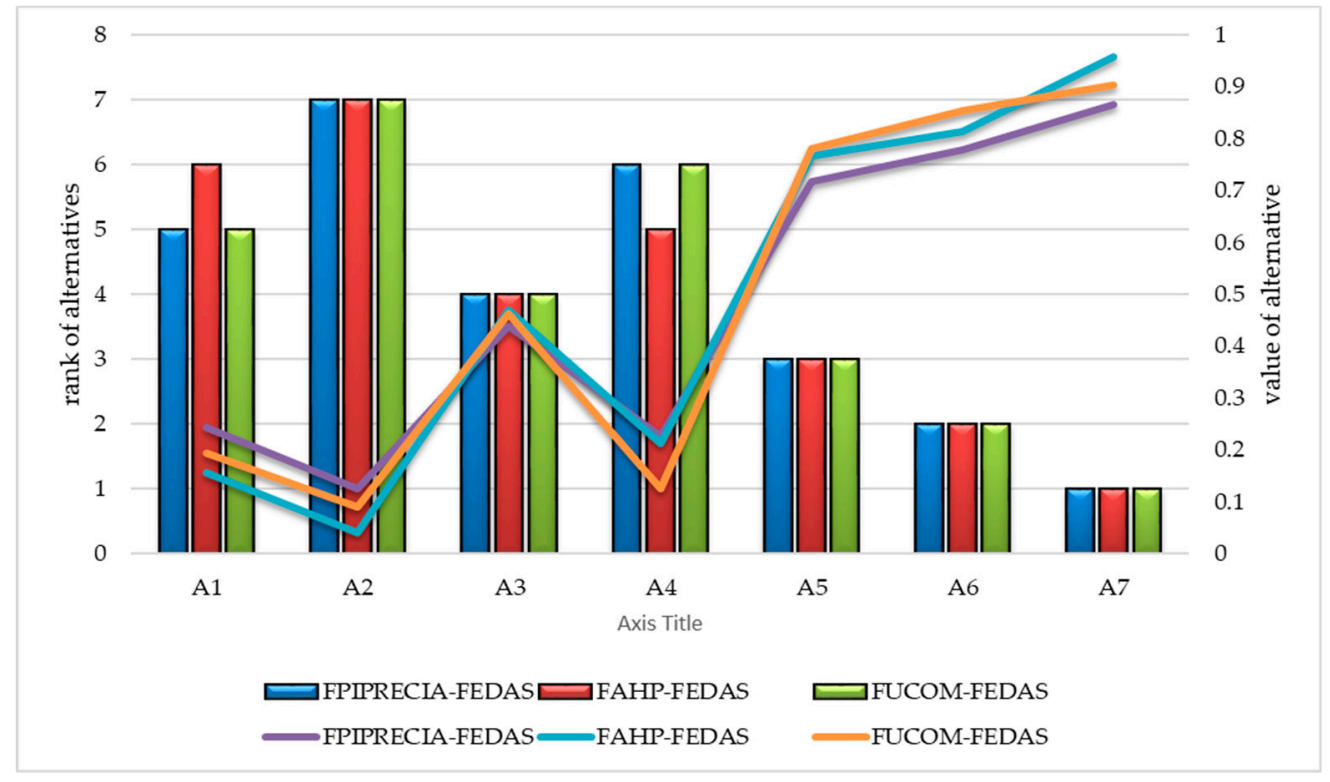

Figure 14. Results obtained using different methods for determining criteria weights.

Applying the above methods for determining the significance of the criteria and including them into the F-EDAS method yield the results presented in Figure 14. In addition to the ranks shown on the left, values of variants on the right are defined. It can be observed that F-PIPRECIA and FUCOM give identical ranks, while, applying F-AHP, there are deviations in the ranks of the first and fourth variants.

\subsection{Additional Correction of Criteria Weights Obtained Using F-AHP}

After presenting the previous results, the stability of the model is additionally determined as changing the significance of particular criteria. Therefore, a sensitivity analysis has been performed, which is presented throughout two parts in this subsection. Figure 15 shows the ranking of variants in all ten scenarios, while Figure 16 shows Spearman's coefficient of correlation for the ranking of variants. In the first set, the three most important criteria reduced the values by $10 \%$, while the others increased by $15 \%$. In the second set, the two most important criteria reduced the values by $15 \%$, while the others increased by $10 \%$. In the third set, the first criterion reduced by $20 \%$, while the others increased by $5 \%$. In next set, the second criterion reduced by $20 \%$, while the others increased by $5 \%$. In the fifth set, the fourth criterion reduced by $20 \%$, while the others increased by $5 \%$. In the next set, the first three criteria have values of 0.25 , the fourth has 0.15 , and the fifth has 0.1 . In the seventh set, the criteria have values as follows: $C_{1}=C_{2}=C_{4}=0.30, C_{3}=0.10$, and the last criterion has a value of zero. In set 8: $C_{1}=C_{2}=C_{4}=0.30, C_{5}=0.10$, and the third criterion has a value of zero. In set 9: $C_{1}=0.34, C_{2}=0.27$, $C_{3}=0.20, C_{4}=0.13, C_{5}=0.06$. In the last set, $C_{1}=0.30, C_{2}=0.20, C_{3}=0.15, C_{4}=0.20, C_{5}=0.15$.

As it can be seen in Figure 15, the seventh variant in seven, from ten formed sets, represents the best solution, while in the other scenarios, the best solution is variant six. The fifth variant is stable in all formed scenarios and has a third position. Variant three and two are also very stable and, only in the first and sixth sets, changing the position. Variant three has position five in the first set, while variant two has position six in the first and sixth sets. The ranking of the first variant varies from the fourth to seventh position in different scenarios, while the fourth variant varies from the fifth to seventh position. We can conclude that with the decrease, the three most important criteria by the $10 \%$ results and ranking of variants are very sensitive. 


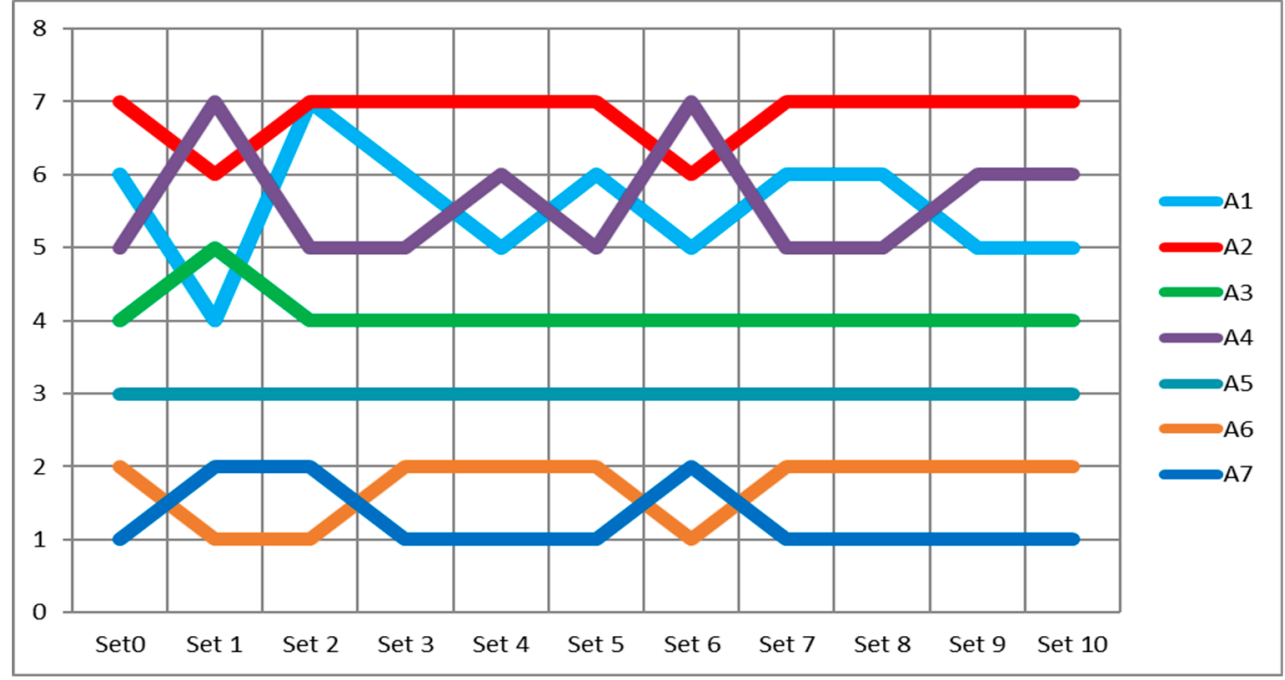

Figure 15. Results of sensitivity analysis of Fuzzy Analytic Hierarchy Process (F-AHP)-F-EDAS changing the significance of criteria.

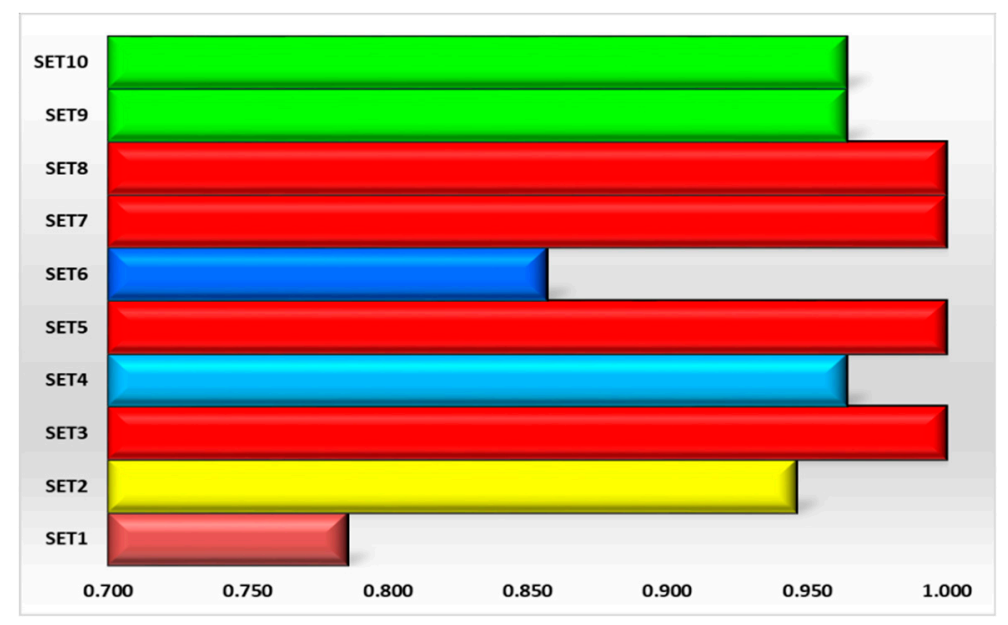

Figure 16. SCC through ten formed scenarios of F-AHP-F-EDAS model.

Figure 16 shows the SCC throughout all scenarios. From Figure 15, it can be seen that the model is sensitive to changes in the weight of the criteria and that each criterion can play an important role in the variant ranking. Spearman's coefficient of correlation has the range of $0.786-1.00$, which represents a high degree of correlation, and the results obtained using the integrated fuzzy model are considered stable. The average SCC value for all ten formed scenarios in relation to the initial rank is 0.948 .

\section{Discussion and Conclusions}

In certain cases, there is risk of insufficient financial resources for the execution of the PSO. The costs for the realization of PSO by the operators that are in a state or local ownership may also affect the possibility of implementing the model. Within the framework of the realization of this model, there are several possible sensitive situations that can appear from the moment of planning to the realization: Poor implementation of "business cost reduction" activities, especially with operators owned by government authorities; the lack of interest in "increasing revenue" in the gross contract, especially with operators owned by the authorities, regardless of whether they are revenue from the sale of tickets or other effects; incomplete and untimely realization of the fee for the execution of the PSO; lack of sufficient financial resources from the authorities to increase the fee for the execution of 
the PSO; the weakness of the state operators in the realization of other effects that can be realized on the basis of the granted right to perform PSO.

In this paper, a dynamic model for optimal application of the PSO system in the PPT process is proposed, which can contribute to the development of appropriate systems for the implementation of PPT services. In addition, it contributes to raising the service quality with the achievement of minimal costs of the functioning of these systems from the aspect of state and local government. By applying this model, it is possible to achieve a large number of effects (increase in passenger transport volume, higher and more stable quality of transport services, reduction in travel costs, better and more efficient cost control, etc.) and achieve significant savings in the functioning of the PPT system. Optimization of the PPT system has an indirect influence on the optimization of transport capacities and improvement in the quality of the transport service with economic quantification and cost savings.

The model was tested in the case of the organization of passenger traffic in the RRS (B\&H). Based on the performed analysis, and in accordance with the task, the implementation of Variant $V_{7}$ is recommended as the most acceptable solution. As good enough solutions, we might accept variants $\mathrm{V}_{6}$ and $\mathrm{V}_{5}$. The contribution of this research represents the possibility for rationalization of the PTT system in RRS. The new F-PIPRECIA-F-EDAS model developed in this research uses the strengths of fuzzy logic and multicriteria decision-making methods. One of the reasons for the F-PIPRECIA method application is its ability to equally handle quantitative and qualitative criteria. One of the reasons for using the F-EDAS method is a mathematical apparatus that assumes the evaluation of variants on the basis of positive and negative deviations from the average solution. The development of the new F-PIPRECIA-F-EDAS model based on TFNs represents the main scientific novelty of this paper. Future research related to this paper should be the implementation of the best variant and post-analysis of PPT systems.

Author Contributions: Conceptualization, S.V. and D.K.; methodology, Ž.S. and D.K.; validation, G.S. and S.M.; investigation, S.V. and S.R.; data curation, S.R.; writing—original draft preparation, Ž.S. and S.M.; writing-review and editing, S.V. and G.S. All authors have read and agreed to the published version of the manuscript.

Funding: This research received no external funding.

Conflicts of Interest: The authors declare no conflict of interest.

\section{References}

1. Stojić, G.; Mladenović, D.; Prentkovskis, O.; Vesković, S. A Novel model for determining public service compensation in integrated public transport systems. Sustainability 2018, 10, 2969. [CrossRef]

2. The European Parliament and the Council of the European Union. On Public Passenger Transport Services by Rail and by Road and Repealing Council Regulations (EEC) Nos 1191/69 and 1107/70, Regulation (EC) No 1370/2007; L 315/1; Official Journal of the European Union; The European Parliament and the Council of the European Union: Brussels, Belgium, 2007.

3. EMTA Barometer of Public Transport in European Metropolitan Areas in 2006. Available online: https: //www.emta.com/IMG/pdf/Barometer_2006_full_Report.pdf (accessed on 17 February 2020).

4. Beck, A. Commercial public bus transport services in Germany: How a market in motion struggles with its regulatory framework. Res. Transp. Econ. 2010, 29, 183-194. [CrossRef]

5. Rojo, M.; dell'Olio, L.; Gonzalo-Orden, H.; Ibeas, A. Inclusion of quality criteria in public bus service contracts in metropolitan areas. Transp. Policy 2015, 42, 52-63. [CrossRef]

6. Vesković, S.; Raičević, V.; Stojić, G.; Milinković, S. A model to estimate the passenger rail liberalisation: The case of serbia. Int. J. Traffic Transp. Eng. 2012, 1, 202-220. [CrossRef]

7. Nash, C.A.; Smith, A.S.J.; van de Velde, D.; Mizutani, F.; Uranishi, S. Structural reforms in the railways: Incentive misalignment and cost implications. Res. Transp. Econ. 2014, 48, 16-23. [CrossRef]

8. Ibarra-Rojas, O.J.; Rios-Solis, Y.A. Synchronization of bus timetabling. Transp. Res. Part B Methodol. 2012, 46, 599-614. [CrossRef]

9. Tirachini, A.; Hensher, D.A. Bus congestion, optimal infrastructure investment and the choice of a fare collection system in dedicated bus corridors. Transp. Res. Part B Methodol. 2011, 45, 828-844. [CrossRef] 
10. Kim, M.; Schonfeld, P. Conventional, flexible, and variable-type bus services. J. Transp. Eng. 2011, 138, $263-273$. [CrossRef]

11. Van Reeven, P. Subsidisation of urban public transport and the mohring effect. J. Transp. Econ. Policy (JTEP) 2008, 42, 349-359.

12. Vuchic, V. Urban Transport Operation, Planning and Economics; John Viley \& Sons Inc.: Hoboken, NJ, USA, 2005.

13. Hanson, S.; Giuliano, G. The Geography of Urban Transportation, 3rd ed.; Guilford Press: New York, NY, USA, 2004.

14. Karabašević, D.; Popović, G.; Stanujkić, D.; Maksimović, M.; Sava, C. An approach for hotel type selection based on the single-valued intuitionistic fuzzy numbers. Int. Rev. 2019, 7-14. [CrossRef]

15. Naeini, A.B.; Mosayebi, A.; Mohajerani, N. A hybrid model of competitive advantage based on Bourdieu capital theory and competitive intelligence using fuzzy Delphi and ism-gray Dematel (study of Iranian food industry). Int. Rev. 2019, 21-35. [CrossRef]

16. Zhou, Y.; Xu, L.; Muhammad Shaikh, G. Evaluating and prioritizing the green supply chain management practices in pakistan: Based on delphi and fuzzy AHP approach. Symmetry 2019, 11, 1346. [CrossRef]

17. Stević, Ž.; Stjepanović, Ž.; Božičković, Z.; Das, D.K.; Stanujkić, D. Assessment of conditions for implementing information technology in a warehouse system: A novel fuzzy piprecia method. Symmetry 2018, 10, 586. [CrossRef]

18. Keshavarz Ghorabaee, M.; Zavadskas, E.K.; Amiri, M.; Turskis, Z. Extended EDAS method for fuzzy multi-criteria decision-making: An application to supplier selection. Int. J. Comput. Commun. Control 2016, 11, 358-371. [CrossRef]

19. Chang, D.Y. Applications of the extent analysis method on fuzzy AHP. Eur. J. Oper. Res. 1996, 95, 649-655. [CrossRef]

20. Pamučar, D.; Stević, Ž.; Sremac, S. A new model for determining weight coefficients of criteria in mcdm models: Full consistency method (fucom). Symmetry 2018, 10, 393. [CrossRef]

21. Stanković, M.; Stević, Ž.; Das, D.K.; Subotić, M.; Pamućar, D. A new fuzzy marcos method for road traffic risk analysis. Mathematics 2020, in press.

22. Fauzi, N.; Nungsiyati, T.; Noviarti, M.; Muslihudin, R.; Irviani, R.; Maseleno, A. Optimal dengue endemic region prediction using fuzzy simple additive weighting based algorithm. Int. J. Pure Appl. Math. 2018, $118,473-478$.

23. Chatterjee, P.; Stević, Ž. A two-phase fuzzy AHP-fuzzy TOPSIS model for supplier evaluation in manufacturing environment. Oper. Res. Eng. Sci. Theory Appl. 2019, 2, 72-90. [CrossRef]

24. Đalić, I.; Stević, Ž.; Karamasa, C.; Puška, A. A novel integrated fuzzy PIPRECIA - interval rough SAW model: Green supplier selection. Decis. Mak. Appl. Manag. Eng. 2020, 3, 126-145. [CrossRef]

25. Marković, V.; Stajić, L.; Stević, Ž.; Mitrović, G.; Novarlić, B.; Radojičić, Z. A novel integrated subjective-objective mcdm model for alternative ranking in order to achieve business excellence and sustainability. Symmetry 2020, 12, 164. [CrossRef]

26. Vesković, S.; Milinković, S.; Abramović, B.; Ljubaj, I. Determining criteria significance in selecting reach stackers by applying the fuzzy PIPRECIA method. Oper. Res. Eng. Sci. Theory Appl. 2020, 3, 72-88. [CrossRef]

27. Stević, Ž.; Vasiljević, M.; Zavadskas, E.K.; Sremac, S.; Turskis, Z. Selection of carpenter manufacturer using fuzzy EDAS method. Eng. Econ. 2018, 29, 281-290. [CrossRef]

28. Stević, Ž.; Vasiljević, M.; Puška, A.; Tanackov, I.; Junevičius, R.; Vesković, S. Evaluation of suppliers under uncertainty: A multiphase approach based on fuzzy AHP and fuzzy EDAS. Transport 2019, 34, 52-66. [CrossRef]

29. Ecer, F. Third-party logistics (3PLs) provider selection via Fuzzy AHP and EDAS integrated model. Technol. Econ. Dev. Econ. 2018, 24, 615-634. [CrossRef]

30. Durmić, E. Evaluation of criteria for sustainable supplier selection using FUCOM method. Oper. Res. Eng. Sci. Theory Appl. 2019, 2, 91-107. [CrossRef]

31. Badi, I.; Abdulshahed, A. Ranking the Libyan airlines by using full consistency method (FUCOM) and analytical hierarchy process (AHP). Oper. Res. Eng. Sci. Theory Appl. 2019, 2, 1-14. [CrossRef]

32. Roszkowska, E.; Kacprzak, D. The fuzzy SAW and fuzzy TOPSIS procedures based on ordered fuzzy numbers. Inf. Sci. 2016, 369, 564-584. [CrossRef]

33. Bojanić, D.; Kovač, M.; Bojanic, M.; Ristic, V. Multi-criteria decision making in defensive operation of guided anti-tank missile battery: An example of hybrid model fuzzy AHP-MABAC. Decis. Mak. Appl. Manag. Eng. 2018, 1, 51-66. [CrossRef] 
34. Božanić, D.; Tešić, D.; Milićević, J. A hybrid fuzzy AHP-MABAC model: Application in the Serbian Army-The selection of the location for deep wading as a technique of crossing the river by tanks. Decis. Mak. Appl. Manag. Eng. 2018, 1, 143-164. [CrossRef]

35. Gangwar, R.; Raghuram, G. Framework for structuring public private partnerships in railways. Case Stud. Transp. Policy 2015, 3, 295-303. [CrossRef]

36. Vesković, S.; Stević, Ž.; Stojić, G.; Rajilić, S.; Vasiljević, M. Application of fuzzy AHP method for profit analysis of railway operators with PSO. In Proceedings of the XVII International Scientific-Expert Conference on Railways -RAILCON, Niš, Serbia, 13-14 October 2016; pp. 105-108.

37. Puška, A.; Kozarević, S.; Stević, Ž.; Stovrag, J. A new way of applying interval fuzzy logic in group decision making for supplier selection. Econ. Comput. Econ. Cybern. Stud. Res. 2018, 52. [CrossRef]

38. Rezaei, P.; Rezaie, K.; Nazari-Shirkouhi, S.; Tajabadi, M.R. Application of fuzzy multi-criteria decision making analysis for evaluating and selecting the best location for construction of underground dam. Acta Polytech. Hung. 2013, 10, 187-205.

(C) 2020 by the authors. Licensee MDPI, Basel, Switzerland. This article is an open access article distributed under the terms and conditions of the Creative Commons Attribution (CC BY) license (http://creativecommons.org/licenses/by/4.0/). 